\title{
Effects of hydrogen induced delay fracture on high-strength steel plate of automobile and the improvement
}

\author{
Fengzhu Liu, Yu Zhao \\ Changchun Automobile Industry Institute, Changchun, Jilin, 130013, China \\ syzhaoy:163.com
}

\begin{abstract}
Delay fracture is an environmental embrittlement occurring when materials, environment and stress interact with each other and also a form of hydrogen induced material deterioration. It is a leading factor inhibiting the further improvement of strength of steel and iron material. Hence this study analyzed the improved low-carbon Mn-B type ultra-high strength steel plate $(1500 \mathrm{MPa})$ which were processed by conventional heat treatment and heating forming technique and explored the effects of tempering temperature and heating forming technique on the performance of hydrogen induced delay fracture, which provides a reference for the actual application of such kind of steel plate.
\end{abstract}

KEY WORDS: Hydrogen induced delay fracture; Environmental management technology.

\section{INTRODUCTION}

$\mathrm{H}$ igh-strength steel is usually mixed with hydrogen during smelting, processing and using. Generally, hydrogen which enters steel is extremely harmful. For many materials, even a trace of hydrogen can induce delay fracture through diffusion and enrichment. Hence the diffusion and enrichment of hydrogen in metals is the premise and bridge for delay fracture [1-3].

Delay fracture of high-strength steel is a manifestation of hydrogen embrittlement of metals. According to the source of hydrogen, hydrogen embrittlement can be typed into environmental hydrogen embrittlement and internal hydrogen embrittlement [4 - 6]. Environmental hydrogen embrittlement is induced by the invasion of hydrogen generated from corrosion reaction which happens when materials are exposed to the air for a long time. For instance, delay fracture may happen to bolt used in bridge if it is exposed to moist air or rain. Internal hydrogen embrittlement is induced by the gathering of hydrogen that enters steels in the process of thermal processing, acid pickling and electroplating towards stress source [7 - 9]. For instance, electroplated bolt may crack in a short time after loading.

Delay fracture can result in the damage of high-strength steels within the designed load-carrying capacity. Materials with higher grades are of higher risks of delay fracture. Delay fracture is difficult to be detected and usually happens suddenly [10]. Recently, accidents induced by hydrogen induced delay fracture of high-strength steels happen frequently. Delay fracture has become a barrier for the development of high-strength steel. A large number of evidences have suggested that, the delay fracture of high strength steel have brought huge threatens to industries such as modern motor, architecture, mechanics and light industry. When the strength of steel is over $1200 \mathrm{MPa}$, the steel would be highly sensitive to hydrogen induced delay fracture [11 - 12]. Till now, several researches have studied the delay fracture behavior of high-strength and ultra high strength steel plat [13]. However, we attach less importance to the delay fracture resistance of low-carbon Mn-B steel plate [14], especially the delay fracture performance of low-carbon Mn-B steel plate which has 
been processed by hot forming. With the rapid development of hot forming technology, it is urgent to evaluate the delay fracture behavior of hot formed ultra high-strength steel plate. On account of this, this study processed a kind of lowcarbon Mn-B ultra high-strength steel plate with conventional thermal processing and hot forming technique and studied the effects of tempering temperature and hot forming process on its hydrogen-induced delay fracture resistance, which can provide a reference for the actual application of such kind of steel plate.

\section{MATERIALS AND METHOD}

\section{Experimental material}

he material used in the test was the improved Mn-B cold-rolled steel plate (1500 MPa) which was self-developed. It was produced using techniques of rotating furnace, external refining, continuous casting and continuous rolling.

The thickness of steel plate was $1.5 \mathrm{~mm}$. Its chemical components and their mass fractions were as follows: $\mathrm{Si}$ (0.85), C (0.20), $\mathrm{Mn}$ (1.60), S (0.002), P (0.006) and B (0.0015). The experimental steel was first heated into $950{ }^{\circ} \mathrm{C}$ and then cooled with water after 20-min insulation. The hardened martensitic structure obtained was tempered at 100,200 and $400{ }^{\circ} \mathrm{C}$ sequentially for $120 \mathrm{~min}$ and then cooled in the air. The process is shown in Tab. 1.

\begin{tabular}{ccc}
\hline No. of samples & Heat treatment system \\
1 & & $/$ \\
2 & $950{ }^{\circ} \mathrm{C} \times 20 \mathrm{~min}$, water cooling & $100^{\circ} \mathrm{C} \times 120 \mathrm{~min}$, air cooling \\
3 & & $200^{\circ} \mathrm{C} \times 120 \mathrm{~min}$, air cooling \\
4 & $400^{\circ} \mathrm{C} \times 120 \mathrm{~min}$, air cooling \\
\hline
\end{tabular}

Table 1: Heat treatment system of experimental materials.

\section{Experimental method}

To test the tensile performance of the experimental material in quenched state at different tempering temperatures, a tensile experiment was carried out on tensile sample using material testing machine. Constant-load notch tensile experiment was used to evaluate the resistance of the experimental material. The ratio of critical fracture stress $\sigma_{c}$ to notch strength $\sigma_{N}$, i.e., delay fracture strength ratio $\sigma_{c} / \sigma_{N}$ was used to evaluate the delay fracture resistance of the experimental materials. The higher the value was, the better the delay fracture resistance was.

To avoid the size effect of thin plate shape samples on hydrogen absorption and dehydrogenation behaviors, the experimental steel plate with a thickness of $6.0 \mathrm{~mm}$ was processed into a round bar sample with a size of $5 \times 40 \mathrm{~mm}$. Then electrochemical hydrogen charging was performed on $\mathrm{NaOH}$ solution $(0.1 \mathrm{~mol} / \mathrm{L})$; the current density used was 4 $\mathrm{mA} / \mathrm{cm}^{2}$ and the process lasted for $72 \mathrm{~h}$. After hydrogen charging and surface grinding, the content of hydrogen in the sample was tested using thermal desorption spectrometry (TDS); the heating temperature was $800{ }^{\circ} \mathrm{C}$ and the heating rate was $100{ }^{\circ} \mathrm{C} / \mathrm{h}$. Activation energy of hydrogen traps in the sample was tested by varying the heating rate of TDS. The content of hydrogen of hydrogen filled sample was measured at different time points; in this way, the diffusion coefficient of hydrogen in the experimental material was calculated. Besides, the notched tensile sample was loaded in corrosive liquid under the effect of critical stress for $100 \mathrm{~h}$. The working segment near the corroded notch was cut using wire cutting. To estimate the critical hydrogen content of the experimental material, the content of hydrogen was measured using TDS as well after grinded with 1000 \# abrasive paper.

Constant-load delay fracture experiment, electronic hydrogen charging experiment and test with TDS were carried out on experimental materials in conventional quenching state and at different tempering temperatures to study the delay fracture resistance as well as behaviors of hydrogen absorption and effusion and discuss over the effects of quenching and tempering temperature on the delay fracture resistance of the experimental materials.

\section{RESULTS AND DISCUSSION}

\section{Mechanical performance of experimental materials}

$\mathrm{F}$ ig. 1 shows the changes of tensile performance of the experimental materials along with tempering temperature. It can be seen that, the experimental material had high strength and good plasticity; tensile strength weakened after tempering at $100{ }^{\circ} \mathrm{C}$, whereas yield strength improved. In different states, elongation fluctuated, but slightly. Only 
when the material was tempered at $400{ }^{\circ} \mathrm{C}$, elongation decreased under the effect of temper embrittlement.

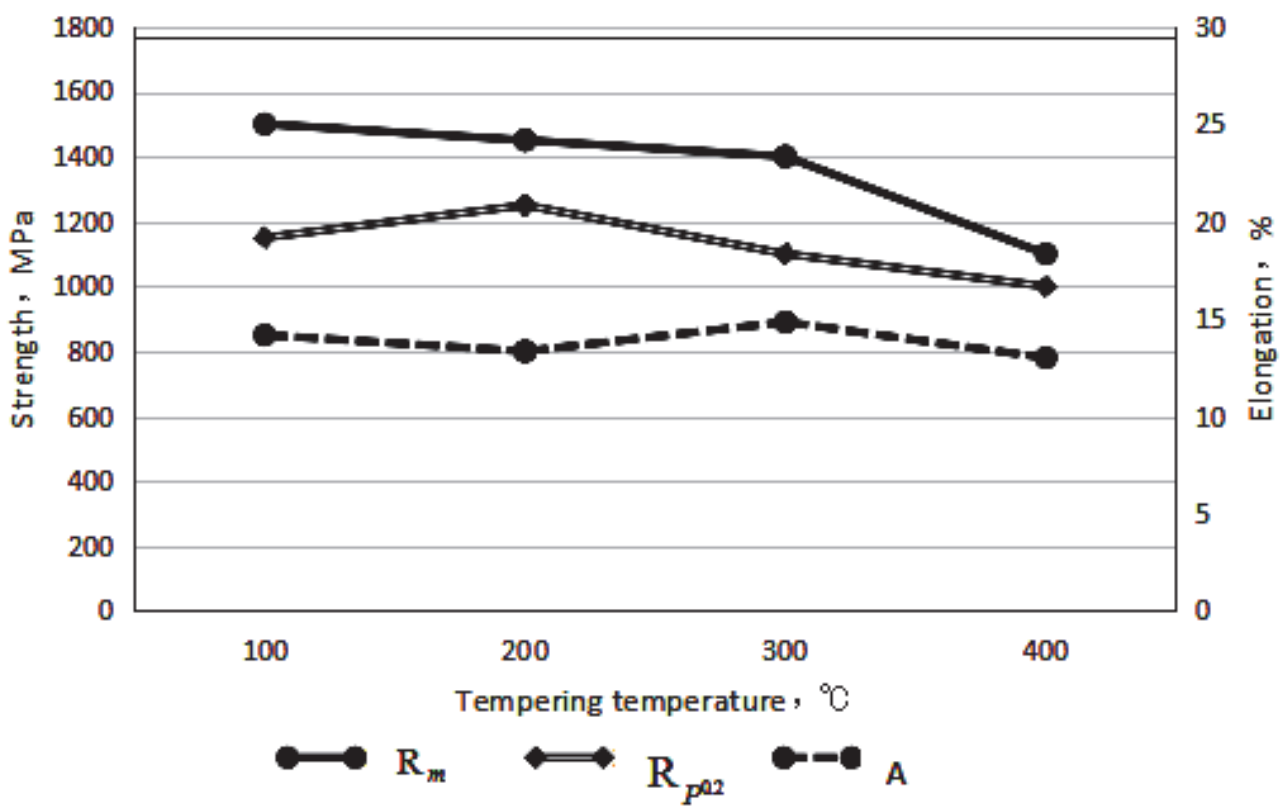

Figure 1: Vibration tendency of the mechanical performance of the experimental materials along with tempering temperature.

\section{The delay fracture resistance of experimental materials}

Fig. 2 and 3 show the curves for applied stress - time of failure (S-T) in notched tensile experiment. It can be seen that, time of failure increased with the decrease of applied stress. Compared to samples in quenching state, the S-T curve of samples at different tempering temperatures moved towards upper right first and then left lower when the tempering temperature rose to $400{ }^{\circ} \mathrm{C}$. It indicated that, tempering processing improve the delay fracture resistance of the experimental materials; and samples processed at tempering temperature of $200{ }^{\circ} \mathrm{C}$ had the highest critical fracture stress and the longest fracture lifespan (Fig. 3).

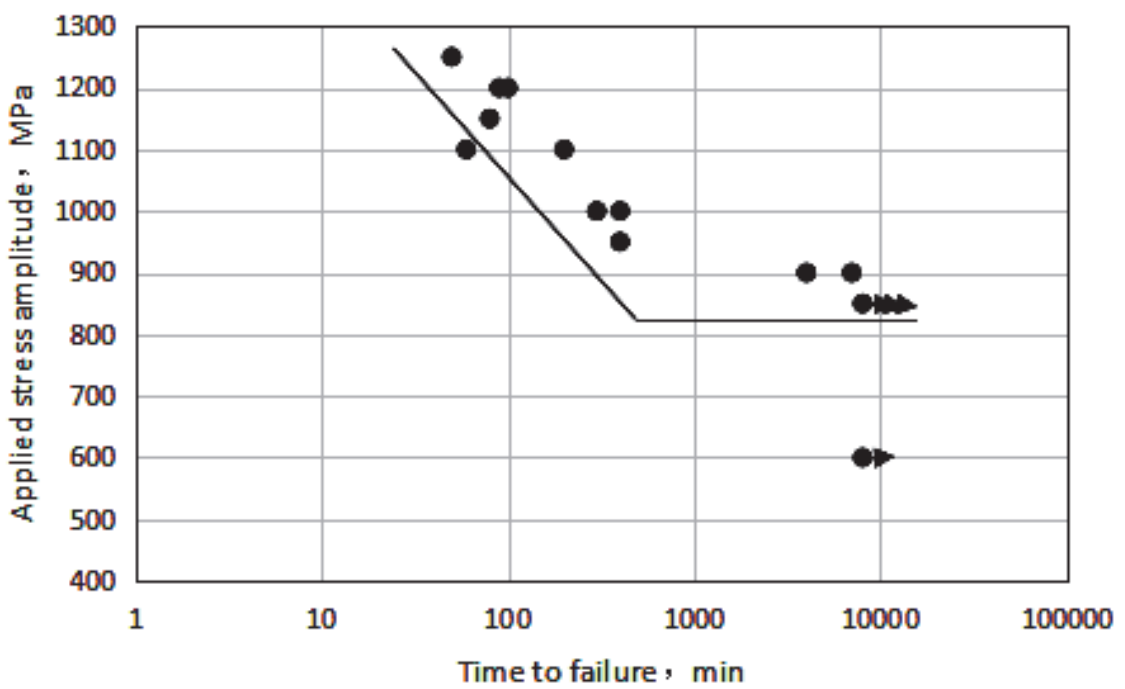

Figure 2: Curves for stress - time of failure of the experimental materials in quenching state in notched tensile experiment.

Results of notched tensile experiment carried out on the experimental materials are shown in Tab. 2. Fig. 4 and 5 show the vibrations of critical fracture stress and delay fracture strength ratio of the experimental materials along with the changes of strength and tempering temperature. It can be seen that, critical fracture stress and delay fracture strength ratio of the experimental materials except for samples processed at a tempering temperature of $400{ }^{\circ} \mathrm{C}$ gradually increased with 
the decrease of tensile strength or the increase of tempering temperature. With the decrease of strength of notch samples, critical fracture stress and delay fracture strength ratio of the samples increased first and then decreased. Though the strength of the samples processed at a tempering temperature of $200{ }^{\circ} \mathrm{C}$ reduced for $6.65 \%$, the critical fracture stress improved for $51.14 \%$ and the delay fracture strength ratio improved for $61.97 \%$. It indicated that, proper tempering processing after quenching could greatly improve the delay fracture performance when the strength was slightly weakened.

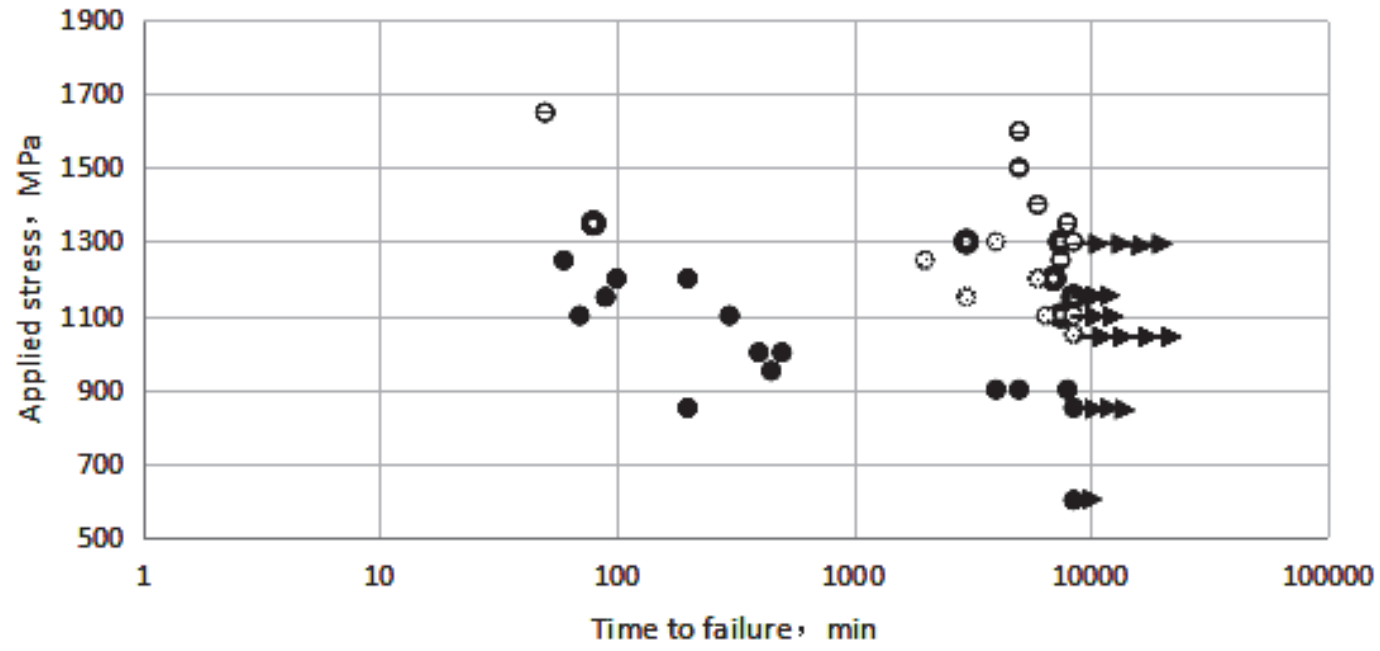

As-quenched $\odot$ Tempered at $100^{\circ} \mathrm{C}$ - Tempered at $200^{\circ} \mathrm{C}$ Tempered at $400^{\circ} \mathrm{C}$

Figure 3: Curves for stress - time of failure of the experimental materials in different states in notched tensile experiment.

\begin{tabular}{ccccc}
\hline & $\begin{array}{c}\text { Quenching } \\
\text { state }\end{array}$ & $\begin{array}{c}100{ }^{\circ} \mathrm{C} \text { tempering } \\
\text { state }\end{array}$ & $\begin{array}{c}200{ }^{\circ} \mathrm{C} \text { tempering } \\
\text { state }\end{array}$ & $\begin{array}{c}400{ }^{\circ} \mathrm{C} \text { tempering } \\
\text { state }\end{array}$ \\
Smooth tensile strength $\mathrm{R}_{\mathrm{m}}, \mathrm{MPa}$ & 1488 & 1466 & 1399 & 1102 \\
Notch tensile strength $\sigma_{\mathrm{N}}, \mathrm{MPa}$ & 1759 & 1781 & 1642 & 1455 \\
Critical fracture stress $\sigma_{\mathrm{c}}, \mathrm{MPa}$ & 874 & 1162 & 1321 & 1134 \\
Delay fracture strength ratio $\sigma_{\mathrm{c}} / \sigma_{\mathrm{N}}$ & 0.497 & 0.652 & 0.805 & 0.780 \\
\hline
\end{tabular}

Table 2: Results of delay fracture experiment.

\section{Hydrogen absorption and effusion behaviors of the experimental materials}

Delay crack of high-strength steel is correlated to the hydrogen in steels and the hydrogen absorbed from the environment and in corrosion process. Hence we explored hydrogen absorption and effusion behaviors of round bar and plate samples.

Hydrogen absorption and hydrogen effusion behaviors of non-bearing experimental materials before and after hydrogen charging.

After the round bar samples in different states were charged with hydrogen for $72 \mathrm{~h}$ at a current density of $4 \mathrm{~mA} / \mathrm{cm}^{2}$, the content of hydrogen was measured using TDS at a heating rate of $100^{\circ} \mathrm{C} / \mathrm{h}$. Besides, the content of hydrogen in samples without hydrogen charging was also measured (Tab. 3).

Generally, hydrogen released at a temperature below $400{ }^{\circ} \mathrm{C}$ is called as diffusible hydrogen, whereas hydrogen released at a temperature higher than $400{ }^{\circ} \mathrm{C}$ is called as non-diffusible hydrogen $[15,16]$. As the delay fracture is the most obvious when the temperature is near to room temperature, delay fracture is considered to be induced by diffusible hydrogen released at room temperature rather than non-diffusible hydrogen released at room temperature [17, 18]. In this study, hydrogen released at a temperature below $300{ }^{\circ} \mathrm{C}$ was regarded as diffusible hydrogen and hydrogen released at a temperature above $300{ }^{\circ} \mathrm{C}$ was as non-diffusible hydrogen. Therefore, the hydrogen corresponding to the first hydrogen effusion peak of materials processed at a relatively low temperature was diffusible hydrogen and the hydrogen corresponding to the second hydrogen effusion peak of materials processed at a relatively high temperature was nondiffusible hydrogen. Obviously, the content of diffusible hydrogen in the samples in quenching state was quite low, so was 
the content of non-diffusible hydrogen in the samples in tempering state. An obvious low-temperature hydrogen effusion peak appeared in the hydrogen effusion curve of the hydrogen charged samples in quenching state or at different tempering temperatures and the peak temperature was about $145^{\circ} \mathrm{C}$; but no obvious changes were observed in the hightemperature hydrogen effusion peak. Besides, the low-temperature peak of hydrogen filled samples in tempering state was the highest. With the increase of tempering temperature, the low-temperature peak of the samples decreased, but the hightemperature peak had no obvious changes. It suggested that, the hydrogen absorbed after hydrogen charging was diffusible hydrogen and the content of non-diffusible hydrogen had no obvious changes.

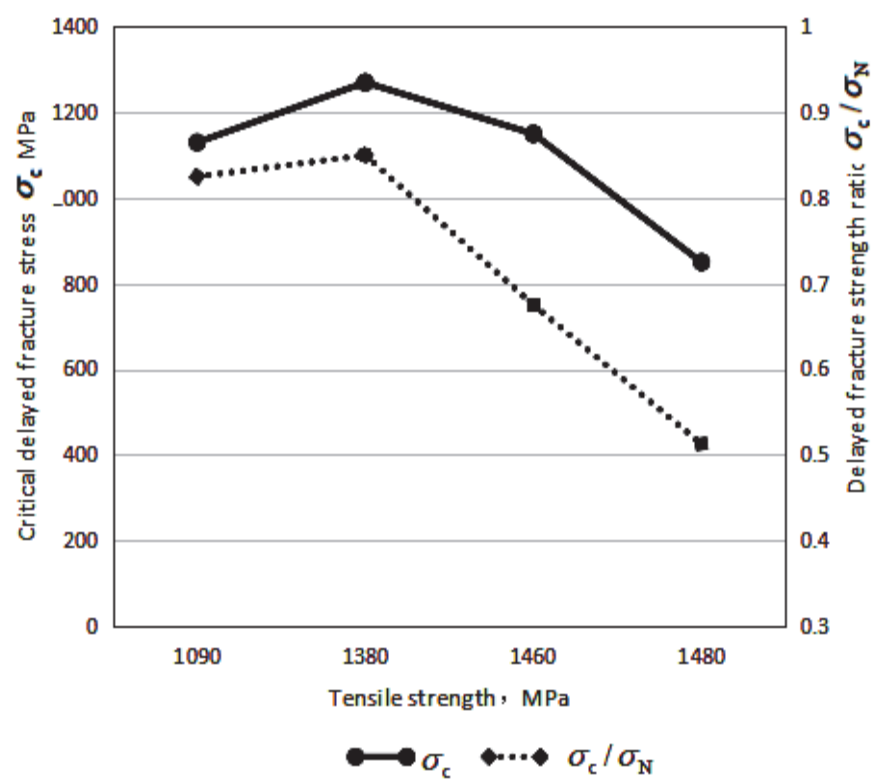

Figure 4: Variation of critical fracture stress and delay fracture ratio of the experimental materials along with the changes of tensile strength.

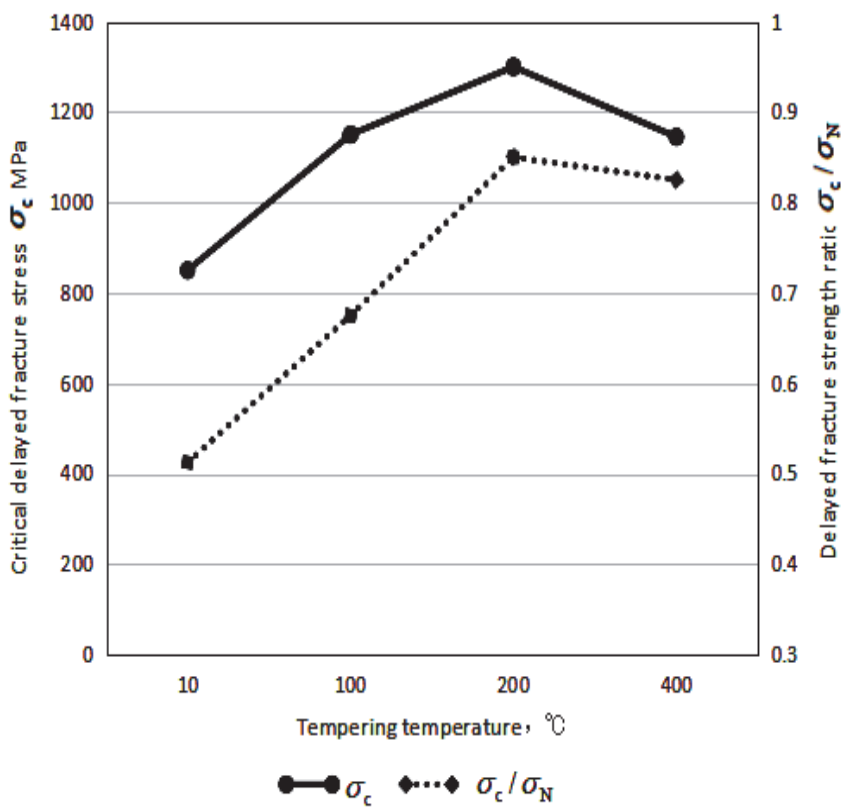

Figure 5: Variation of clinical fracture stress and delay fracture ratio of the experimental materials along with the changes of tempering temperature. 
Fig. 6 shows the variation of the hydrogen content of the experimental materials in different states along with the changes of tempering temperature. It can be seen that, the content of hydrogen in different states before hydrogen charging were similar; the content of diffusible hydrogen was quite low; except for samples processed at a tempering temperature of 100 ${ }^{\circ} \mathrm{C}$, the content of non-diffusible hydrogen in samples in different states was highly consistent; the content of hydrogen significantly improved after hydrogen charging, a slight increase in non-diffusible hydrogen and a significantly increase in diffusible hydrogen; as the tempering temperature increased, the content of hydrogen charged reduced (the content of diffusible hydrogen decreased and the content of non-diffusible hydrogen remained unchanged).

\begin{tabular}{|c|c|c|c|c|c|}
\hline \multicolumn{2}{|c|}{ State of samples } & $\begin{array}{l}\text { Quenching } \\
\text { state }\end{array}$ & $\begin{array}{c}100{ }^{\circ} \mathrm{C} \\
\text { tempering } \\
\text { state }\end{array}$ & $\begin{array}{c}200^{\circ} \mathrm{C} \\
\text { tempering } \\
\text { state }\end{array}$ & $\begin{array}{c}400{ }^{\circ} \mathrm{C} \\
\text { tempering } \\
\text { state }\end{array}$ \\
\hline \multirow{3}{*}{$\begin{array}{c}\text { Samples without } \\
\text { hydrogen } \\
\text { charging } \\
\text { (original state) }\end{array}$} & $\begin{array}{l}\text { The content of diffusible } \\
\text { hydrogen (ppm) }\end{array}$ & 0.0176 & 0.0081 & 0.0009 & 0.0031 \\
\hline & $\begin{array}{l}\text { The content of non- } \\
\text { diffusible hydrogen (ppm) }\end{array}$ & 0.0741 & 0.1677 & 0.0791 & 0.0834 \\
\hline & $\begin{array}{l}\text { Total content of hydrogen } \\
(\mathrm{ppm})\end{array}$ & 0.0909 & 0.1758 & 0.0801 & 0.0857 \\
\hline \multirow{3}{*}{$\begin{array}{l}\text { Hydrogen-filled } \\
\text { samples }\end{array}$} & $\begin{array}{l}\text { The content of diffusible } \\
\text { hydrogen(ppm) }\end{array}$ & 0.8629 & 0.6201 & 0.5452 & 0.4441 \\
\hline & $\begin{array}{l}\text { The content of non- } \\
\text { diffusible hydrogen (ppm) }\end{array}$ & 0.1134 & 0.0951 & 0.1402 & 0.1443 \\
\hline & $\begin{array}{l}\text { Total content of hydrogen } \\
(\mathrm{ppm})\end{array}$ & 0.9771 & 0.7136 & 0.6866 & 0.5882 \\
\hline
\end{tabular}

Table 3: The content of hydrogen of the experimental materials in different states before and after hydrogen charging (non-bearing, round bar samples).

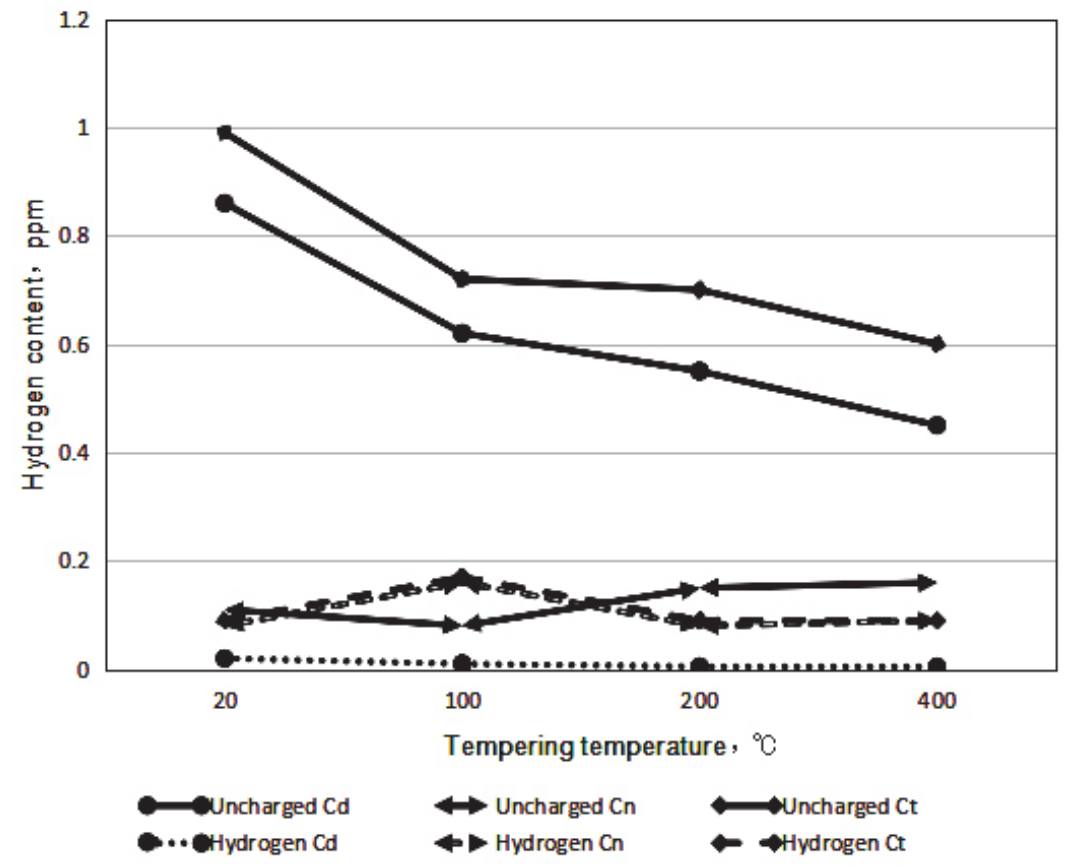

Figure 6: Vibration of the content of hydrogen of round bar samples in different states before and after hydrogen charging $\left(\mathrm{C}_{\mathrm{d}}\right.$ : the content of diffusible hydrogen; Cn: the content of non-diffusible hydrogen; Ct: the content of hydrogen).

Hydrogen absorption and effusion behaviors of experimental materials before and after loading

The notch tensile samples were loaded for 100 hours in corrosive liquid under critical stress. Then the corroded part was cut down. After surface clearance, it was put into TDS to measure behaviors of hydrogen absorption and effusion, and the measurements results are shown in Tab. 4 and Fig. 8. It can be seen that, the content of hydrogen in samples in four 
different states differs little before loading, and the hydrogen involved was non-diffusible hydrogen; the content of hydrogen improved after 100-h loading in corrosive liquid, and the hydrogen involved was also non-diffusible hydrogen; the content of hydrogen in samples in quenching state was the lowest, while the content of hydrogen in samples processed at a tempering temperature of $200^{\circ} \mathrm{C}$ was the highest, four times that of the sample in quenching state and two times that of the samples processed at a tempering temperature of $100{ }^{\circ} \mathrm{C}$ and $400{ }^{\circ} \mathrm{C}$.

\begin{tabular}{|c|c|c|c|c|c|}
\hline \multicolumn{2}{|c|}{ State of samples } & $\begin{array}{l}\text { Quenching } \\
\text { state }\end{array}$ & $\begin{array}{c}100^{\circ} \mathrm{C} \\
\text { tempering state }\end{array}$ & $\begin{array}{c}200{ }^{\circ} \mathrm{C} \\
\text { tempering state }\end{array}$ & $\begin{array}{c}400{ }^{\circ} \mathrm{C} \\
\text { tempering state }\end{array}$ \\
\hline \multirow{3}{*}{ Samples before loading } & $\begin{array}{l}\text { The content of } \\
\text { diffusible } \\
\text { hydrogen (ppm) }\end{array}$ & 0.0119 & 0.0081 & 0.0099 & 0.0185 \\
\hline & $\begin{array}{l}\text { The content of } \\
\text { non-diffusible } \\
\text { hydrogen (ppm) }\end{array}$ & 0.1160 & 0.0958 & 0.1121 & 0.1278 \\
\hline & $\begin{array}{c}\text { Total content of } \\
\text { hydrogen }\end{array}$ & 0.1281 & 0.1045 & 0.1221 & 0.1466 \\
\hline \multirow{3}{*}{ Samples after loading } & $\begin{array}{l}\text { The content of } \\
\text { diffusible } \\
\text { hydrogen (ppm) }\end{array}$ & 0.0839 & 0.0534 & 0.1629 & 0.0938 \\
\hline & $\begin{array}{l}\text { The content of } \\
\text { non-diffusible } \\
\text { hydrogen (ppm) }\end{array}$ & 0.3385 & 0.6466 & 1.6319 & 1.7968 \\
\hline & $\begin{array}{l}\text { Total content of } \\
\text { hydrogen (ppm) }\end{array}$ & 0.4228 & 0.6997 & 1.7949 & 0.8518 \\
\hline
\end{tabular}

Table 4. The content of hydrogen of experimental materials in different states before and after loading (plate samples)

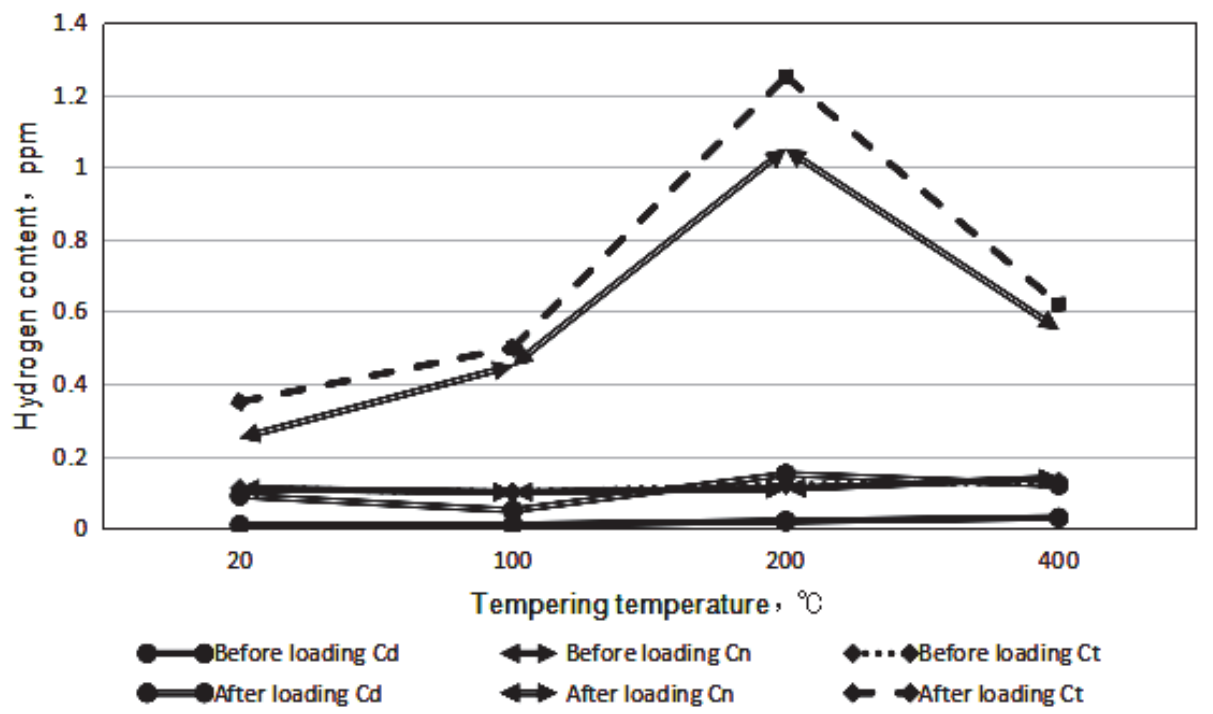

Figure 7: The content of hydrogen of experimental materials in different states before and after loading (plate samples).

Activation energy of hydrogen trap of experimental materials

The peak temperature of hydrogen effusion peak would change when heating rate in thermal analysis changed. Activation trap corresponding to hydrogen effusion peak can be calculated according to the variation of the peak temperature $[19 \sim$ 20]. It is because that, hydrogen in traps can be gradually released by overcoming trap potential barrier when hydrogen filled samples are heated at a certain heating rate and the process is controlled by the bulk diffusion of hydrogen in samples. As the capability of every kind of trap trapping hydrogen is fixed, a peak value will appear in the curve of the correlation between hydrogen effusion rate and temperature under certain heating condition. The capability of trap 
trapping hydrogen can be estimated qualitatively according to the peak value. The hydrogen effusion peak temperature would change if the heating rate was changed; when heating rate increases and heating time reduces, hydrogen effusion peak moves towards high temperature.

The correlation between heating rate and hydrogen effusion peak temperature [21] is:

$$
\frac{\mathrm{E}_{a} \varphi}{\mathrm{RT}_{P}^{2}}=\mathrm{Ae}^{\frac{\mathrm{E}_{a}}{R T_{P}}}
$$

In the formula,

$E_{a}$ refers to activation energy of hydrogen trap,

$\varphi$ refers to heating rate;

$T_{p}$ refers to hydrogen effusion peak temperature,

A is a constant

$\mathrm{R}$ is a gas constant.

After taking the logarithm of both sides of formula (1) and differentiation, we get

$$
\frac{\partial \ln \left(\varphi / T_{P}^{2}\right)}{\partial\left(1 / T_{P}\right)}=-\frac{E_{a}}{R}
$$

It can be known from formula (2) that, $\ln \left(\varphi / T_{P}{ }^{2}\right)$ and $1 / T_{P}$ was in a linear correlation. Hence Ea could be calculated using linear fitting method.

Hydrogen effusion peak temperature of hydrogen effusion curves of experimental samples processed at different heating rates is shown in Tab. 5. The correlation between $\ln \left(\varphi / T_{P}{ }^{2}\right)$ and $1 / T_{P}$ could be obtained in Fig. 8. Besides, the value of

\begin{tabular}{|c|c|c|c|}
\hline $\begin{array}{l}\text { Heating rate, } \\
{ }^{\circ} \mathrm{C} / \mathrm{h}\end{array}$ & State of samples & $\begin{array}{l}\text { Hydrogen effusion peak } \\
\text { temperature of diffusible } \\
\text { hydrogen, }{ }^{\circ} \mathrm{C}\end{array}$ & $\begin{array}{c}\text { Hydrogen effusion peak } \\
\text { temperature of non-diffusible } \\
\text { hydrogen, }{ }^{\circ} \mathrm{C}\end{array}$ \\
\hline \multirow{4}{*}{100} & Quenching state & 152 & 396 \\
\hline & $100^{\circ} \mathrm{C}$ tempering state & 129 & 411 \\
\hline & $200{ }^{\circ} \mathrm{C}$ tempering state & 132 & 411 \\
\hline & $400{ }^{\circ} \mathrm{C}$ tempering state & 126 & 390 \\
\hline \multirow{4}{*}{200} & Quenching state & 201 & 438 \\
\hline & $100{ }^{\circ} \mathrm{C}$ tempering state & 179 & 430 \\
\hline & $200{ }^{\circ} \mathrm{C}$ tempering state & 186 & 427 \\
\hline & $400{ }^{\circ} \mathrm{C}$ tempering state & 160 & 408 \\
\hline \multirow{4}{*}{400} & Quenching state & 260 & 465 \\
\hline & $100{ }^{\circ} \mathrm{C}$ tempering state & 251 & 455 \\
\hline & $200{ }^{\circ} \mathrm{C}$ tempering state & 244 & 453 \\
\hline & $400{ }^{\circ} \mathrm{C}$ tempering state & 222 & 447 \\
\hline
\end{tabular}
$\mathrm{E}_{a} / \mathrm{R}$ was obtained after solving slope with linear fitting, and then the value of activation energy $E_{a}$ was obtained.

Table 5: Hydrogen effusion peak temperature of hydrogen effusion curves of experimental materials processed by different heating rate. 

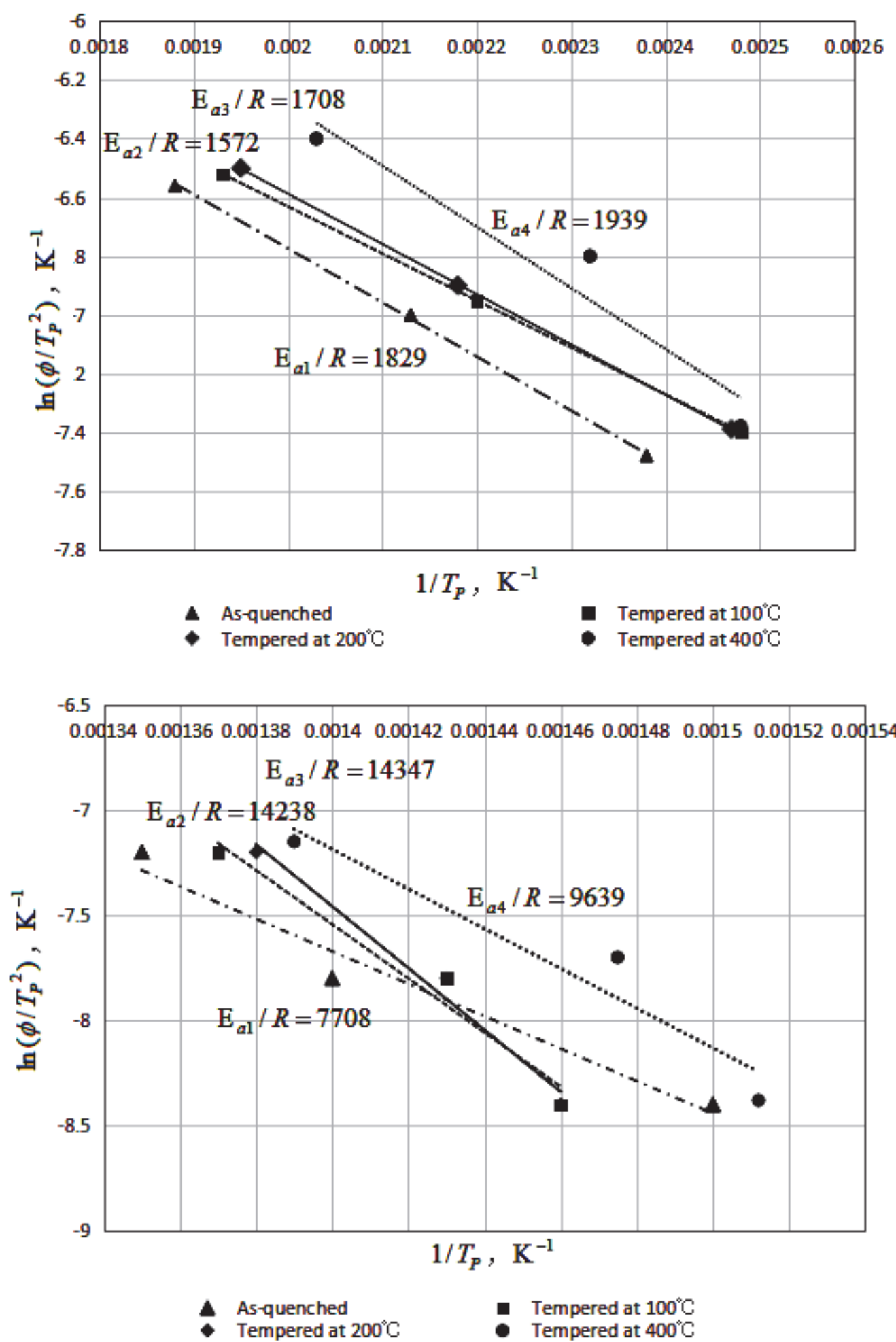

Figure 8. The correlation between $\ln \left(\varphi / T_{P}{ }^{2}\right)$ and $1 / T_{P}$ of experimental materials: a) diffusible hydrogen; b) non-diffusible hydrogen).

Tab. 6 shows that, activation energy of diffusible hydrogen trap was close to hydrogen activation energy of $\mathrm{M}_{3} \mathrm{C}$ carbide in $42 \mathrm{CrMo}$ steel processed at a tempering temperature of $600{ }^{\circ} \mathrm{C}(13.4 \mathrm{kj} / \mathrm{mol})[22]$ as well as hydrogen trap activation energy of $\mathrm{Fe}_{3} \mathrm{C}(18.5 \mathrm{~kJ} / \mathrm{mol})$ and hydrogen trap activation energy of grain boundary $(17.2 \mathrm{~kJ} / \mathrm{mol})[23]$. 


\begin{tabular}{|c|c|c|c|c|}
\hline & $\begin{array}{l}\text { Quenching } \\
\text { state }\end{array}$ & $\begin{array}{l}100{ }^{\circ} \mathrm{C} \\
\text { tempering state }\end{array}$ & $\begin{array}{l}200{ }^{\circ} \mathrm{C} \\
\text { tempering state }\end{array}$ & $\begin{array}{l}400{ }^{\circ} \mathrm{C} \\
\text { tempering state }\end{array}$ \\
\hline $\begin{array}{l}\text { Activation energy of diffusible hydrogen, } \\
\qquad \mathrm{KJ} / \mathrm{mol}\end{array}$ & 15.3 & 12.9 & 14.3 & 16.2 \\
\hline $\begin{array}{c}\text { Activation energy of non-diffusible } \\
\text { hydrogen, } \mathrm{KJ} / \mathrm{mol}\end{array}$ & 63.9 & 118.9 & 119.6 & 79.5 \\
\hline
\end{tabular}

Table 6: Hydrogen trap activation energy of experimental materials.

\section{Diffusion of hydrogen in experimental materials}

It was found that, hydrogen-induced crack was closely correlated to the local concentration of hydrogen [24]. As for diffusible hydrogen, local concentration is determined by average content and diffusion process. Therefore, it is important to study the diffusion process of diffusible hydrogen in samples. Fig. 9 shows the vibration of the content of diffusible hydrogen in steels along with the changes of time. It can be seen that, the content of diffusible hydrogen in experimental materials decreased with the increase of storage time; when the storage time exceeds $72 \mathrm{~h}$, the concentration of diffusible hydrogen in experimental steels was around $0.15 \times 10^{-6}$.

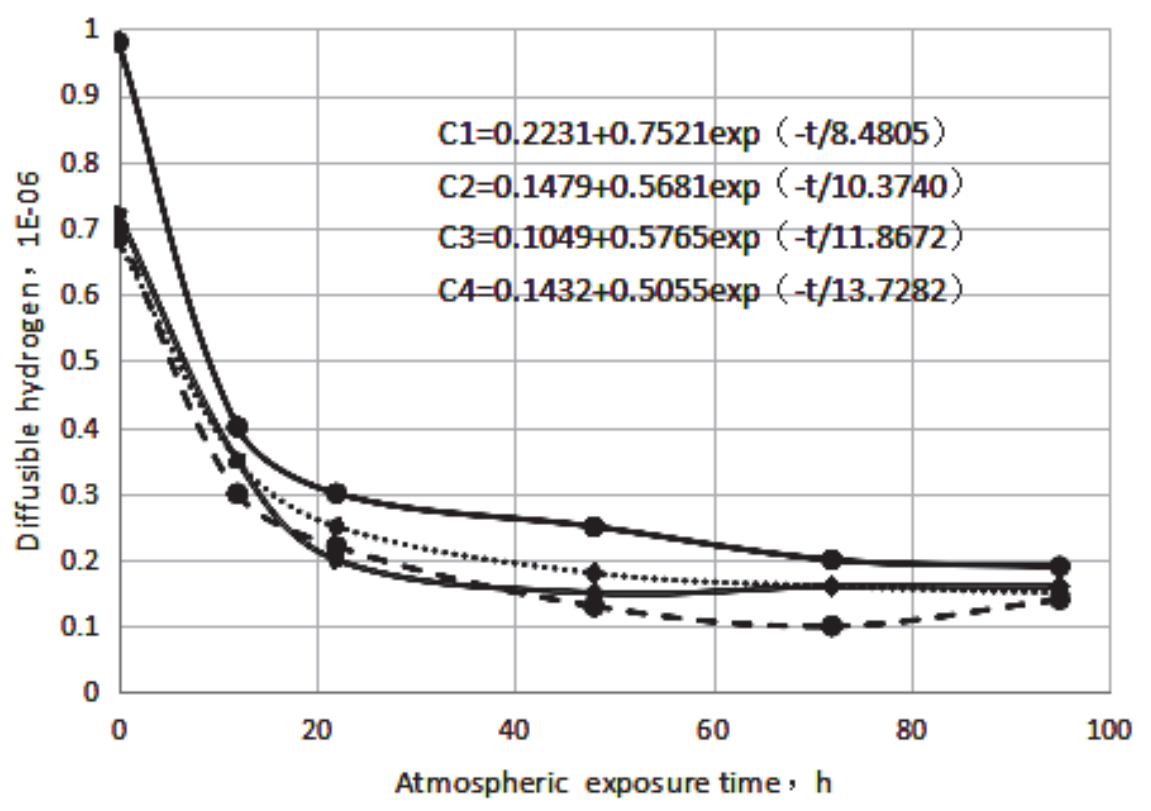

Figure 9: Effects of storage time after hydrogen charging on the concentration of diffusible hydrogen of experimental materials in different states.

Carnerio Filho et al. [25] once studied the diffusion of hydrogen in steels based on the rules of decline of hydrogen content of hydrogen-filled round bar samples which were stored for different periods of time. The equation of diffusion of hydrogen in steels is:

$$
C_{t}=C_{\infty}+0.72\left(C_{0}-C_{\infty}\right) \exp \left(-22.2 D t / d^{2}\right)
$$

In the formula, $C_{t}$ refers to the concentration of diffusible hydrogen in steels at time point $t ; C \infty$ refers to the concentration of diffusible hydrogen of experimental materials when $t$ is equal to $\infty$; $\mathrm{C}_{0}$ refers to the concentration of diffusible hydrogen when $\mathrm{t}=0$; $\mathrm{d}$ refers to the diameter of sample; $\mathrm{D}$ stands for diffusion coefficient of hydrogen in experimental materials. The experimental results of experimental materials in different states were substituted into formula (3); regression analysis results are shown in Fig. 9. It can be seen that, the diffusion coefficients of hydrogen in materials processed by quenching, $100{ }^{\circ} \mathrm{C}$ tempering, $200{ }^{\circ} \mathrm{C}$ tempering and $400{ }^{\circ} \mathrm{C}$ tempering were $\mathrm{D}_{1}=3.71 \times 10^{-7}, \mathrm{D}_{2}=2.98 \times$ 
$10^{-7}, \mathrm{D}_{3}=2.66 \times 10^{-7}$ and $\mathrm{D}_{4}=2.31 \times 10^{-7} \mathrm{~cm}^{2} / \mathrm{s}$. Obviously, with the increase of tempering temperature, diffusion coefficients of experimental materials would decrease.

To sum up, as for the improved $\mathrm{Mn}-\mathrm{B}$ steel plate $(1500 \mathrm{MPa})$, the delay fracture resistance of experimental material in quenching state is the lowest, but tempering processing can significantly enhance the delay crack resistance. The delay fracture resistance of the materials processed at $200{ }^{\circ} \mathrm{C}$ tempering temperature was the highest on the condition that the strength of experimental materials decreased slightly. When tempering temperature was too high, for example, $400{ }^{\circ} \mathrm{C}$, then diffusion coefficient of hydrogen at room temperature was weakened due to the significant decrease of the strength, but the resistance was still high than that of materials processed by quenching. With the increase of tempering temperature, the diffusion coefficient of hydrogen at room temperature decreased. The content of non-diffusible hydrogen of experimental materials in corrosive fluid under critical stress showed an obvious improvement after loading. The quantity of hydrogen bearing by the samples in quenching state under critical stress was the lowest, while the quantity of hydrogen of the samples processed at $200{ }^{\circ} \mathrm{C}$ tempering temperature was the highest. Under the effect of critical stress and after 100-h loading in corrosive liquid, the content of hydrogen in samples showed a remarkable increase; besides, the quantity of hydrogen processed by heat forming was higher than that of samples processed by quenching and samples processed by quenching and $100{ }^{\circ} \mathrm{C}$ tempering, leading to the high delay fracture resistance. Hence, hot forming processing can ensure a high delay fracture resistance of experimental materials and tempering processing can further improve the delay fracture resistance of experimental materials.

\section{REFERENCES}

[1] Koyama, M., Akiyama, E., Tsuzaki, K., Hydrogen-induced delayed fracture of a Fe-22Mn-0.6C steel pre-strained at different strain rates. Scripta Materialia, 66(11) (2012) 947-950.

[2] Zhang, C. L., Liu, Y. Z., Chao, J., et al. Effects of Niobium and Vanadium on Hydrogen-Induced Delayed Fracture in High Strength Spring Stee 1. Journal of Iron \& Steel Research International, 18(6) (2011) 49-53.

[3] Zhang, S., Huang, Y., Sun, B., et al. Effect of Nb on hydrogen-induced delayed fracture in high strength hot stamping steels. Materials Science \& Engineering A, 626 (2015) 136-143.

[4] Ogata, T., Evaluation of Hydrogen Embrittlement by Internal High-Pressure Hydrogen Environment in Specimen. Journal of the Japan Institute of Metals, 72(2) (2008) 125-131.

[5] Araújo, B. A., Travassos, G. D., Silva, A. A., et al., Experimental Characterization of Hydrogen Embrittlement in API 5L X60 and API 5L X80 Steels. Key Engineering Materials, 478 (2011) 34-39.

DOI:10.4028/www.scientific.net/KEM.478.34.

[6] Mallick, A., Das, S., Mathur, J., et al. Internal reversible hydrogen embrittlement leads to engineering failure of cold drawn wire. Case Studies in Engineering Failure Analysis, 1(2) (2013) 139-143.

[7] Zucca, G., Mocci, A., Tirilló, J., et al. Hydrogen Embrittlement and Fatigue Fracture of a Crankshaft of an Internal Combustion Engine. Procedia Engineering, 109 (2015) 202-209. DOI: 10.1016/j.proeng.2015.06.213.

[8] Mori, K., Lee, E. W., Frazier, W. E., et al. Effect of Tempering and Baking on the Charpy Impact Energy of Hydrogen-Charged 4340 Steel. Journal of Materials Engineering \& Performance, 24(1) (2015)329-337.

[9] Rajabipour, A., Melchers, R. E., Capacity of pitting corroded pipes under hydrogen assisted cracking. International Journal of Hydrogen Energy, 40(30) (2015) 9388-9399. DOI: 10.1016/j.ijhydene.2015.05.077.

[10] Han, S. Z., Hui, W. J., Liu, R. P., et al. Effect of tempering temperature on hydrogen-induced delayed fracture behavior of 30CrMnSiA steel. Transactions of Materials \& Heat Treatment, 35(7) (2014)114-119.

[11] Zhang, Y. J., Zhou, C., Hui, W. J., et al. Effect of C Content on Hydrogen Induced Delayed Fracture Behavior of MnB Type Steels. Journal of Iron \& Steel Research, 26(5) (2014) 49-55.

[12] Bai, X. M., Gong, J. M., Wang, Y. F., Prediction of hydrogen induced delayed fracture initiation time of high strength steel using cohesive zone modeling. Journal of Shanghai Jiaotong University, 46(7) (2012) 1079-1083.

[13] Kuduzović, A., Poletti, M. C., Sommitsch, C., et al. Investigations into the delayed fracture susceptibility of 34CrNiMo6 steel, and the opportunities for its application in ultra-high-strength bolts and fasteners. Materials Science \& Engineering A, 590(2) (2014) 66-73.

[14] Li, F. F., Fu, M. W., Lin, J. P., et al. Experimental and theoretical study on the hot forming limit of $22 \mathrm{MnB} 5$ steel. International Journal of Advanced Manufacturing Technology, 71(1-4) (2014) 297-306. DOI: $10.1007 /$ s00170-013-5468-x.

[15] Dariusz, F., Grzegorz, R., Effect of shielded-electrode wet welding conditions on diffusion hydrogen content in deposited metal. Welding International, 25(3) (2011) 166-171. 
[16] Ji, W. W., Gong, H. R., Adsorption and diffusion of hydrogen on Ti, Al, and TiAl surfaces. International Journal of Hydrogen Energy, 39(11) (2014) 6068-6075.

[17]Ji, C., Xinguo, R., Xin-Zheng, L., et al. On the room-temperature phase diagram of high pressure hydrogen: an ab initio molecular dynamics perspective and a diffusion Monte Carlo study. Journal of Chemical Physics, 141(2) (2014) 024501-024501.

[18] Fu-Chun, H., Yung-Yu, C., Tsung-Tsong, W., A room temperature surface acoustic wave hydrogen sensor with Pt coated $\mathrm{ZnO}$ nanorods. Nanotechnology, 20 (6) (2009) 2643-2646.

[19] Silverstein, R., Eliezer, D., Hydrogen trapping mechanism of different duplex stainless steels alloys. Journal of Alloys \& Compounds, 644 (2015) 280-286. DOI: 10.1016/i.jallcom.2015.04.176.

[20] Wei, F. G., Tsuzaki, K., Quantitative analysis on hydrogen trapping of TiC particles in steel. Metallurgical \& Materials Transactions A, 37(2) (2006) 331-353.

[21] Rojas, H., Fierro, J. L. G., Reyes, P., The solvent effect in the hydrogenation of citral over Ir and $\mathrm{Ir}-\mathrm{Fe} / \mathrm{TiO}{ }_{2}$ catalysis. Journal of the Chilean Chemical Society, 52(2) (2007)1155-1159.

[22] Tur, C., Khaleeli, Z., Ciccarelli, O., et al. Complementary roles of grey matter MTR and T2 lesions in predicting progression in early PPMS. Journal of Neurology Neurosurgery \& Psychiatry, 82(4) (2011) 423-428. DOI: $10.1136 /$ innp.2010.209890.

[23] Choo, W. Y., Lee, J. Y., Hydrogen trapping phenomena in carbon steel. Journal of Materials Science, 17(7) (1982) 1930-1938.

[24] Wang, M., Akiyama, E., Tsuzaki, K., Determination of the critical hydrogen concentration for delayed fracture of high strength steel by constant load test and numerical calculation. Corrosion Science, 48(8) (2006) 2189-2202.

[25] Filho, C. J. C., Mansur, M. B., Modenesi, P. J., et al. The effect of hydrogen release at room temperature on the ductility of steel wire rods for pre-stressed concrete. Materials Science \& Engineering A, 527(18) (2010) 4947-4952. 